\title{
Kuolemaan johtaneet maataloustapaturmat Suomessa vuosina 1988-1999
}

\author{
Päivi Rissanen ${ }^{1)}$ ja Kirsti Taattola ${ }^{2}$ \\ 1)Kuopion aluetyöterveyslaitos, PL 93, 70701 KUOPIO, paivi.rissanen@ttl.fi \\ 2)Työterveyslaitos, PL 93, 70701 KUOPIO, kirsti.taattola@ttl.fi
}

\section{Johdanto}

Maatalous on yksi tapaturma-alttiimpia toimialoja. Maa- ja metsätalouden töissä vakavan tapaturman riski on noin kymmenkertainen hallintotöihin verrattuna (Työ- ja terveys Suomessa v. 1997). Käytettävissä ei ole ollut kattavia tietoja maatilan töissä tai työympäristössä sattuneista kuolemaan johtaneista tapaturmista. Tämän tutkimuksen tarkoitus oli selvittää maataloustöissä tai maatilalla tapahtuneita kuolemaan johtaneita tapaturmia ja tapaturmiin johtaneita tekijöitä sekä pohtia keinoja tapaturmien torjumiseksi.

\section{Aineisto ja menetelmät}

Työterveyslaitos on järjestelmällisesti kerännyt tietoja kuolemaan johtaneista traktoritapaturmista vuodesta 1975 ja muista maatalouden kuolemaan johtaneista tapaturmista vuodesta 1976 lähtien. Tämä selvitys perustuu vuosilta 1988-1999 kerättyihin tietoihin.

Vuosittain on lähetetty nimismiespiireille, vuodesta 1997 lähtien kihlakunnille, kysely niiden alueella maataloustöissä sattuneista kuolemaan johtaneista tapaturmista. Tiedot on kerätty samalla lomakkeella koko tutkimuskauden ajan. Kysely on koskenut erikseen traktoritapaturmia ja erikseen muita maatilan hoidossa, maatilan rakennustoiminnassa tai metsätöissä sattuneita kuolemaan johtaneita tapaturmia. Myös lasten ja eläkeläisten tapaturmat ovat tulleet ilmi poliisiviranomaisille suunnatussa kyselyssä.

Kysely on keskittynyt tapaturmiin, jotka ovat johtaneet kuolemaan. Muihin tapaturman vaikutuksiin tai lääketieteelliseen kuolemansyyhyn ei ole kiinnitetty huomiota. Tapaturman kuvaus on käsittänyt tapaturman ja sitä edeltäneet tapahtumat niin laajasti kuin ne on pystytty jälkeenpäin selvittämään.

\section{Tulokset ja tulosten tarkastelu}

Kuolemaan johtaneita maataloustapaturmia sattui keskimäärin 16-17 vuosittain (kuva 1). Tapaturmaisten kuolemien määrä vaihteli 11:sta v. 1998 21:een v. 1992. Kuolemaan johtaneiden tapaturmien määrä pysytteli suuruusluokaltaan samalla tasolla, vaikka maatalousyrittäjien määrä samaan aikaan väheni 190100:sta 111700:aan eli 41 prosenttia. Siten kuolemaan johtaneet maataloustapaturmat suhteessa maatalousyrittäjien määrään ovat yleistyneet.

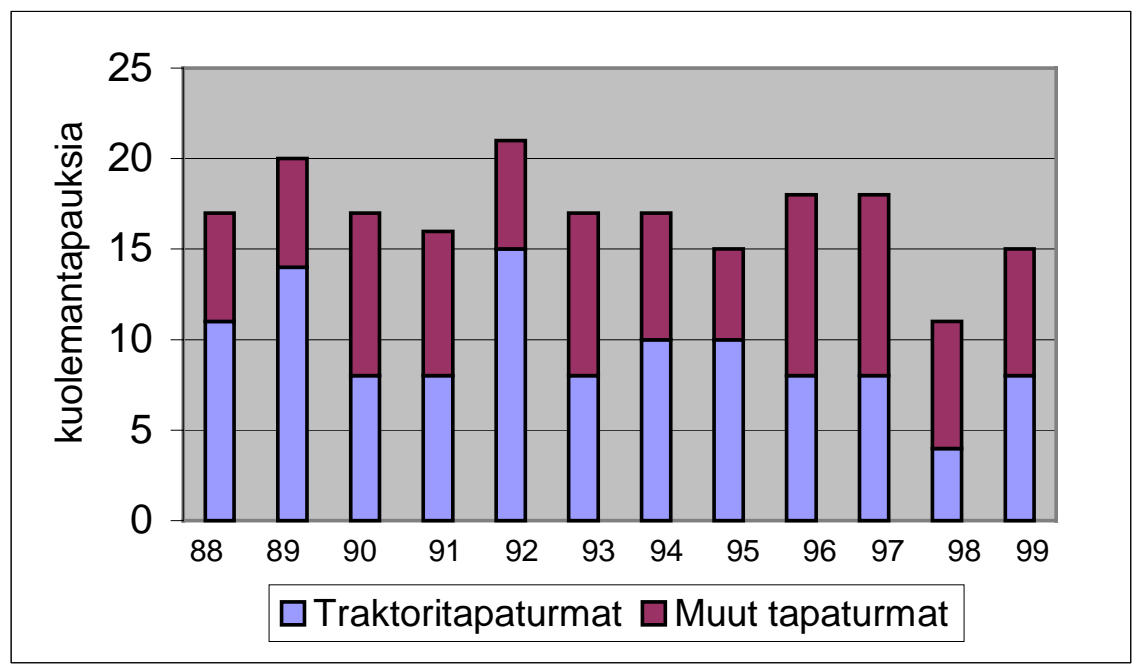

Kuva 1. Kuolemaan johtaneet maataloustapaturmat vuosina 1988-1999 


\section{Tapaturman uhri}

Tapaturman uhreista suurin osa $(69,3 \%)$ oli työikäisiä. Yli 65-vuotiaita oli 21,8 prosenttia ja alle 15vuotiaita 8,9 prosenttia uhreista. Traktoritapaturmissa alle 15 -vuotiaiden osuus oli 11,6 prosenttia ja muissa tapaturmissa 5,6 prosenttia. Uhrien ikä vaihteli yhdestä 86 vuoteen. Suurimman ikäryhmän muodostivat 50-59 -vuotiaat, traktoritapaturmissa 60-69 -vuotiaat (kuva 2).

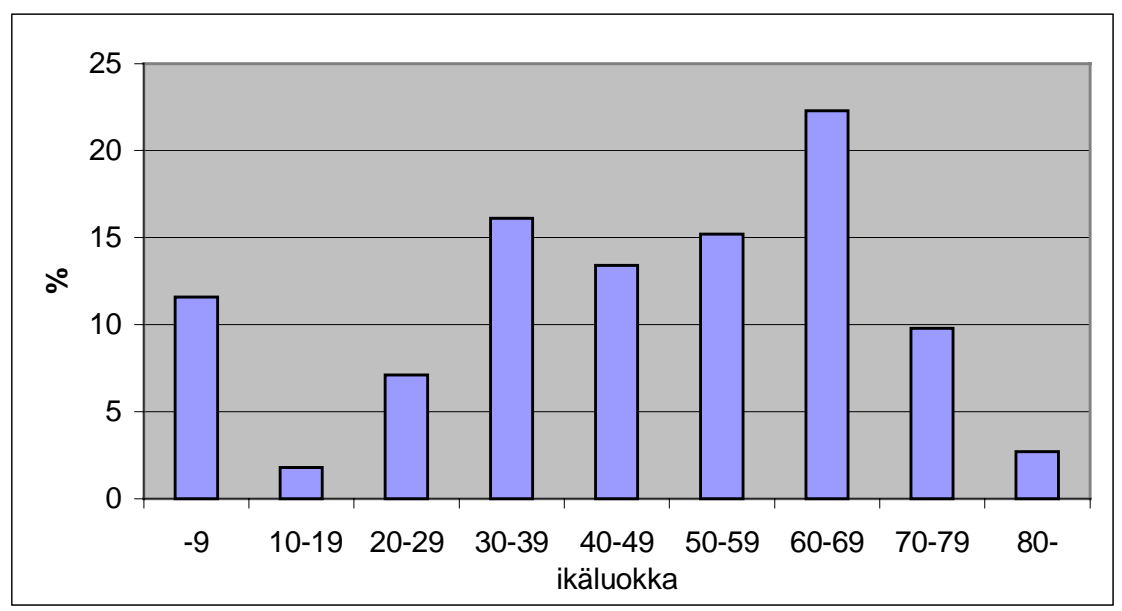

Kuva 2. Uhrien ikäjakauma, traktoritapaturmat.

Uhreista valtaosa oli miehiä (taulukko 1). Alle 15-vuotiaita lapsia kuoli yhteensä 18, joista 12 poikaa ja 6 tyttöä.

Taulukko 1. Uhrin sukupuoli

\begin{tabular}{lrrrrrr} 
& \multicolumn{2}{c}{ Traktoritapaturmat } & \multicolumn{2}{c}{ Muut tapaturmat } & \multicolumn{2}{c}{ Kaikki tapaturmat } \\
& $\mathrm{n}$ & $\%$ & $\mathrm{n}$ & $\%$ & $\mathrm{n}$ & $\%$ \\
\hline Miehet & 96 & 85,7 & 80 & 88,9 & 176 & 87,1 \\
Naiset & 3 & 2,7 & 5 & 5,6 & 8 & 4,0 \\
Lapset (alle 15 v.) & 13 & 11,6 & 5 & 5,6 & 18 & 8,9 \\
\hline & 112 & 100,0 & 90 & 100,0 & 202 & 100,0
\end{tabular}

Tuloksista nähdään, että tyypillinen kuolemaan johtaneen tapaturman uhri oli keskimääräistä iäkkäämpi miespuolinen maatalousyrittäjä. Miesten suurempi tapaturma-alttius on todettu useissa tutkimuksissa (Kisner ja Pratt 1997, Layne ja Landen 1997, Pekkarinen ja Anttonen 2000). Maatalousyrittäjien eläkelaitoksen tapaturmatilastojen (2001) mukaan noin kolme neljäsosaa kaikista maataloustapaturmien uhreista on ollut miehiä. Suutarisen (1991) tutkimuksessa vuoden 1987 traktoritapaturmista $92 \%$ uhreista oli miehiä. Myös ikääntymisen vaikutus tapaturmien todennäköisyyden lisääntymiseen on todettu lukuisissa tutkimuksissa (Ciez 1997, Kisner ja Pratt 1997, Reiling 1997, Hard ym. 1999).

\section{Traktoritapaturmat: onnettomuustyyppi}

Yleisin onnettomuustyyppi oli traktorin kaatuminen joko sivuttain tai taaksepäin ympäri (taulukko 2). Kaatuneista 31 traktorista 26:ssa (84 \%:ssa) ei ollut turvahyttiä. Viidessä kaatumistapaturmassa uhri menehtyi turvahytistä huolimatta.

Turvahyttikään ei kestä, mikäli kolari on todella raju, esimerkiksi traktori pyörähtää useamman kerran ympäri. Turvahytti ei myöskään anna riittävää suojaa, jos ovet eivät ole paikoillaan. Kuljettaja ei saa ajon aikana avata ovea ja kurkkia ulos hytin ulkopuolelle. Mikäli traktori on pysäytetty viettävään maastoon, on traktoriin noustava ylärinteen puolelta.

Oli myös tilanteita, joissa turvahytistä oli haittaa tai se oli jopa kuoleman aiheuttaja. Esimerkiksi kuljettaja löi äkkipysähdyksessä kuolettavasti päänsä hytin rakenteisiin. Joissakin tapaturmissa hytin myös todettiin estäneen näkyvyyttä.

Suojaamaton voimansiirtoakseli oli selkeästi tapaturman syynä neljässä tapauksessa. Nämä tapaukset ajoittuvat kaikki 1990-luvun puolivälin jälkeen. 
Taulukko 2. Onnettomuustyyppi

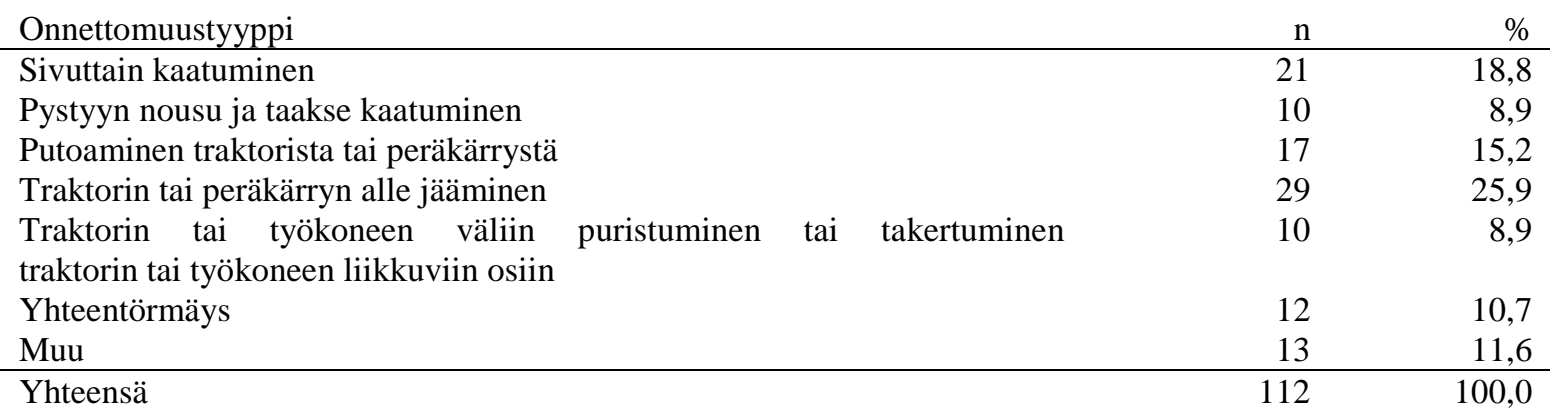

\section{Traktoritapaturmat: tapaturmatilanteeseen johtaneet tekijät}

Kyselylomakkeessa pyydettiin viranomaisia nimeämään kaksi tärkeintä tapaturman syytä. Tärkeimpänä tapaturman syynä viranomaiset pitivät varomattomuutta. Se oli mainittu tapaturman pääasiallisena syynä 27,7 prosentissa tapaturmia. Väärä työmenetelmä tai toimintatapa oli syynä 25,0 prosentissa tapaturmia ja viallinen kone 6,3 prosentissa tapaturmia. Uhreista 17,0 prosenttia oli alkoholin vaikutuksen alaisia.

Tapaturman syiden selvittäminen jälkikäteen on usein vaikeaa. Varsinkin, jos uhri on työskennellyt yksin eikä tapahtumalla ole silminnäkijöitä, perustuu tapahtumien kulkua koskeva selvitys olettamuksiin. Jälkeenpäin voidaan todeta koneiden viallisuus tai väärä toimintatapa, mutta uhrin osuus tapahtumiin, kuten kiire, tietoinen riskinotto tai huolimattomuus, jää oletusten varaan. Uhrin humalatila selvitetään verikokeella, mutta muuten uhrin onnettomuutta edeltävää tilaa kuten väsymystä on vaikea todeta.

\section{Traktoritapaturmat: työ tapaturman sattuessa}

Siirtotyöt ja peltotyöt olivat vaarallisimpia traktoritöitä, niissä menehtyi yhteensä noin 40 prosenttia uhreista (taulukko 3). Seuraavaksi vaarallisimpia olivat työt, joissa oli jouduttu kosketuksiin koneiden kanssa muulloin kuin koneita varsinaiseen työtehtävään käytettäessä, ts. korjaus- ja huoltotöissä tai työkoneiden kiinnityksessä tai irrotuksessa. Näissä tapaturmissa menehtyi 14,3 prosenttia uhreista.

Taulukko 3. Työ tapaturman sattuessa, traktorityöt

\begin{tabular}{lrr} 
Työ & $\mathrm{n}$ & $\%$ \\
\hline Siirtotyö & 23 & 20,5 \\
Peltotyöt & 21 & 18,8 \\
Traktorin tai työkoneen korjaus/huolto tai traktorin tai työkoneen & 16 & 14,3 \\
kiinnitys/irrotus/säätö tai traktorin käynnistys & & \\
Kiinni juuttuneen traktorin irrotus/hinaus & 6 & 5,4 \\
Sadonkäsittely, varastointi & 12 & 10,7 \\
Metsätyö & 4 & 3,8 \\
Lumityö & 6 & 5,4 \\
Muu työ & 10 & 8,9 \\
Ei työssä, ei tietoa & 14 & 12,5 \\
\hline Yhteensä & 112 & 100,0
\end{tabular}

\section{Muut tapaturmat: työ tapaturman sattuessa}

Muista kuin traktoritapaturmista vaarallisimpia olivat rakennustyöt (taulukko 4), joihin tässä sisältyvät myös purkamis- ja kaivutyöt. Kohtalokkaita onnettomuustilanteita syntyi, kun rakennuksia purettaessa purkutyö tehtiin väärässä järjestyksessä alhaalta ylöspäin, tai kaivutyössä kaivannon reunoja ei tuettu sortumien estämiseksi. Koneiden huolto- ja kunnossapitotöissä sattui kuolemaan johtaneita tapaturmia, kun kone oli nostettu ylös korjausta varten tukematta sitä. Sadonkäsittelyssä sattuneista tapaturmista voidaan mainita tyypillisinä onnettomuuksina viljasiiloon tukehtuminen sekä säilörehun teossa sattuneet tapaturmat. Kotieläinten hoidossa tyypillinen kuolemaan johtanut tapaturma oli joutuminen sonnin ruhjomaksi ja metsätöissä kaatuvan puun alle jääminen. 
Taulukko 4. Työ tapaturman sattuessa, muut tapaturmat

\begin{tabular}{lrr} 
Työ & $\mathrm{n}$ & $\%$ \\
\hline Rakentaminen, purkaminen, kaivutyöt & 26 & 28,9 \\
Koneiden huolto ja kunnossapito & 8 & 8,9 \\
Peltotyöt, sadonkäsittely & 9 & 10,0 \\
Kotieläinten hoito & 15 & 16,7 \\
Metsätyöt & 13 & 14,4 \\
Muut työt & 19 & 21,1 \\
\hline Yhteensä & 90 & 100,0
\end{tabular}

\section{Johtopäätökset}

Kuolemaan johtaneiden tapaturmien tapaturmatekijät voidaan jakaa kolmeen ryhmään:

1. Työympäristön ja työvälineiden puutteet

2. Inhimilliset tekijät: riskinottotaipumus ja alentunut toimintakyky

3. Häiriö normaalissa työnkulussa

Yksikin näistä tekijöistä riittää aiheuttamaan tapaturman, mutta tapaturman todennäköisyys on sitä suurempi mitä useampi riskitekijöistä on voimassa.

Työympäristön ja työvälineiden puutteet sinänsä ovat harvoin olleet tapaturman yksinomaisena syynä, mutta ne ovat altistaneet tapaturmille. Koneiden suojavarusteiden puutteellinen kunto, kuten traktorin suojaamaton voimanottoakseli, on ollut osatekijänä monessa tapaturmassa. Pimeys, ahtaus, liukkaus ja rikkinäiset koneet ja rakenteet ovat vaaratekijöitä. Myös työskentelytilojen likaisuus ja epäjärjestys lisäävät tapaturmariskiä.

Inhimilliset erehdykset aiheuttavat vakavia seurauksia etenkin työturvallisuudeltaan puutteellisessa ympäristössä. Kiire, stressi ja väsymys lisäävät tapaturman todennäköisyyttä. Alkoholi vähäisessäkin määrin nautittuna lisää itsevarmuutta ja riskinottohalua ja heikentää arvostelukykyä. Alkoholia nauttineella on suurempi todennäköisyys joutua tapaturmatilanteeseen ja pienempi todennäköisyys selvitä tilanteesta vahingoittumattomana kuin selvällä.

Lapset ja eläkeläiset ovat tapaturmien riskiryhmiä. Pienten lasten päivähoito on järjestettävä niin, ettei heitä tarvitse ottaa työpaikalle ilman valvontaa. Isojen lasten osallistuessa työntekoon on huolehdittava riittävästä työhön perehdyttämisestä ja jatkuvasta työnohjauksesta. Eläkeläiset auttavat maatilan töissä mielellään, mutta heidän työ- ja toimintakykynsä on yleensä alentunut. Eläkeläisten osallistuessa tilan töihin on etukäteen harkittava, millaiset työt ovat heille turvallisia.

Kolmas riskitekijä on häriö normaalissa työnkulussa. Varsin usein vakava tapaturma sattuu poikkeavassa tilanteessa, kun yritetään torjua tai korjata jonkin jo sattuneen vahingon seurauksia, kuten irrottaa kiinni juuttunutta traktoria tai ottaa kiinni karanneita eläimiä. Äkillisessä tilanteessa varovaisuus unohtuu ja otetaan suurempia riskejä kuin normaalisti.

\section{Kirjallisuus}

Ciez, J. 1997. Age of Farmers and Vulnerability to Frequency and Severity of Accidents. Proceedings of the 13th Triennal Congress of the International Ergonomics Association: 15-17. 506 p. Helsinki.

Hard, D. L., Myers J. R., Snyder, K. A., Casini, V. J., Morton, L. L., Cianfrocco, R. \& Fields, J. 1999. Identifying Work-related Fatalities in the Agricultural Production Sector Using Two National Occupational Fatality Surveillance Systems, 1990-1995. J. Agric. Safety \& Health 5(2):155-169.

Kisner, S. M. \& Pratt, S. G. 1997. Occupational fatalities among older workers in the United States: 19801991. J. Occup. Environ. Med. 39(8): 715- 721.

Layne, L. A. \& Landen, D. D. 1997. A descriptive analysis of nonfatal occupational injuries to older workers, using a national probability sample of hospital emergency departments. J. Occup. Environ. Med. 39(9): 855-865.

Maatalousyrittäjien eläkelaitos 2001. MATA-työtapaturmatilastot 1988-1999.

Pekkarinen, A. ja Anttonen, H. 2000. Pohjois-Suomessa syntyneiden tapaturmat 30 ikävuoteen saakka. Työ ja ihminen 1/2000: 37-47. Työterveyslaitos.

Reiling, J. 1997. Agricultural Injuries in Norway. Proceedings of the 13th Triennal Congress of the International Ergonomics Association: 63-65. Helsinki.

Suutarinen J. 1991. Traktoritapaturmat 1987. Tutkimustiedote N:o 62. 50 p. Helsingin yliopisto, maatalousteknologian laitos. Helsinki.

Työterveyslaitos 1997. Työ- ja terveys Suomessa v. 1997. 168 p. Helsinki. 